\title{
ReVIEW
}

\section{Telomere regulation in pluripotent stem cells}

\author{
Yan Huang1, Puping Liang1', Dan Liü ${ }^{2,3,4}$, Junjiu Huang ${ }^{1 凶}$, Zhou Songyang $^{1,4 \bowtie}$ \\ ${ }^{1}$ Key Laboratory of Reproductive Medicine of Guangdong Province, the First Affiliated Hospital and Key Laboratory of Gene \\ Engineering of the Ministry of Education, School of Life Sciences, Sun Yat-sen University, Guangzhou 510275, China \\ ${ }^{2}$ Cell-Based Assay Screening Core, Baylor College of Medicine, One Baylor Plaza, Houston, TX 77030, USA \\ ${ }^{3}$ Dan L. Duncan Cancer Center, Baylor College of Medicine, One Baylor Plaza, Houston, TX 77030, USA \\ ${ }^{4}$ Verna and Marrs Mclean Department of Biochemistry and Molecular Biology, Baylor College of Medicine, One Baylor Plaza, \\ Houston, TX 77030, USA \\ $\bowtie$ Correspondence: hjunjiu@mail.sysu.edu.cn (J. Huang), songyang@bcm.edu (Z. Songyang) \\ Received January 12, 2014 Accepted January 23, 2014
}

\begin{abstract}
Pluripotent stem cells (PSCs) have the potential to produce any types of cells from all three basic germ layers and the capacity to self-renew and proliferate indefinitely in vitro. The two main types of PSCs, embryonic stem cells (ESCs) and induced pluripotent stem cells (iPSCs), share common features such as colony morphology, high expression of Oct4 and Nanog, and strong alkaline phosphatase activity. In recent years, increasing evidences suggest that telomere length represents another important internal factor in maintaining stem cell pluripotency. Telomere length homeostasis and its structural integrity help to protect chromosome ends from recombination, end fusion, and DNA damage responses, ensuring the divisional ability of mammalian cells. PSCs generally exhibit high telomerase activity to maintain their extremely long and stable telomeres, and emerging data indicate the alternative lengthening of telomeres (ALT) pathway may play an important role in telomere functions too. Such characteristics are likely key to their abilities to differentiate into diverse cell types in vivo. In this review, we will focus on the function and regulation of telomeres in ESCs and iPSCs, thereby shedding light on the importance of telomere length to pluripotency and the mechanisms that regulate telomeres in PSCs.
\end{abstract}

KEYWORDS telomere, pluripotent stem cells, alternative lengthening of telomeres (ALT), regulators

\section{TELOMERES}

Telomeres are hexametric repeats of (TTAGGG) $n$ at the chromosomal ends in mammalian cells. During the process of DNA synthesis and cell division, telomeres are shortened as a result of the incomplete replication of linear chromosomes, which is called "end-replication problem". Telomere attrition, which can cause chromosome recombination, endto-end fusion, DNA damage, and genome instability, represents one of the nine hallmarks of aging (Lopez-Otin et al., 2013). Many pieces of evidence, including studies of telomerase null mouse models and diseases with premature aging phenotypes such as dyskeratosis congenita (DC), support the notion that telomere shortening is rate limiting for mammalian lifespan and age-related diseases (Blasco et al., 1997; Herrera et al., 1999; Mason et al., 2005).

Usually, telomere length is maintained by the telomerase, containing the reverse transcriptase TERT and the RNA template TERC, as well as associating proteins such as the ribonucleoprotein dyskerin (DKC1) (Cohen et al., 2007). Telomerase is responsible for the de novo telomere extension, to prevent telomere exhaustion after multiple rounds of cell division (Greider and Blackburn, 1985, 1989). In addition, the telomere region is bound by a six-protein complex called shelterin/telosome, containing TRF1, TRF2, TPP1, POT1, TIN2 and RAP1, which is crucial for maintaining the structure and function of telomeres (de Lange, 2005; Liu et al., 2004; Xin et al., 2008).

In most cases, the telomerase is only activated in stem cells, germ cells, certain white blood cells, and cancers. In a significant number of cases, however, telomeres can be maintained without the telomerase, through possible mechanisms such as homologous recombination, which has been termed alternative lengthening of telomeres (ALT). ALT has been found to occur in about $10 \%-15 \%$ cancers and is often characterized by co-localization of telomeres with the promyelocytic leukemia (PML) bodies (known as ALT-associated PML bodies (APBs)), exceedingly heterogeneous 
telomere length, extra-chromosomal DNA circles, and high frequencies of telomere sister chromatid exchange (T-SCE) (Cesare and Reddel, 2010; Chung et al., 2012). ALT tends to occur in tumors such as osteosarcoma and soft tissue sarcomas derived from mesenchymal or neuroepithelial origin (Cesare and Reddel, 2010; Henson et al., 2005; Scheel et al., 2001). Interestingly, it was found that ALT and telomerase pathway could coexist in human cells under certain circumstances (Cerone et al., 2001). By using a telomeretagged transgenic mouse strain, ALT was recently found to exist in normal mouse somatic cells, but not in the germline (Neumann et al., 2013). Furthermore, it was found that during the early embryo cleavage stage, telomeres are also lengthened by an ALT-like mechanism (Liu et al., 2007).

Increasing evidences indicate that telomeres are tightly linked to epigenetic regulation. Many heterochromatin features can be found in mammalian telomeric or subtelomeric domains, such as trimethylation of H3K9 and H4K20 (Garcia-Cao et al., 2004; Gonzalo et al., 2005), HP1 enrichment (Lachner et al., 2001), low levels of acetylated $\mathrm{H} 3$ and $\mathrm{H} 4$ (Benetti et al., 2007a), and DNA hypermethylation in subtelomeric region (Gonzalo et al., 2006). These "silenced" features in the nucleosome help to maintain a compressed chromatin structure and telomere length homeostasis.

\section{PLURIPOTENT STEM CELLS}

Pluripotent stem cells, including the well-studied ESCs and emerging iPSCs, promise great potential applications in the medical and drug field. ESCs were first isolated from the mouse inner cell mass (ICM) of blastocysts in 1981 (Evans and Kaufman, 1981; Martin, 1981). In recent years, ESCs can also be derived from somatic cell nuclear transfer embryos (ntESCs), parthenogenetic embryos (pESCs), and androgenetic embryos (aESCs). In 2006, the Yamanaka group successfully obtained induced pluripotent stem cells (iPSCs) by introducing four transcriptional factors into mouse as well as human somatic cells (Takahashi et al., 2007; Takahashi and Yamanaka, 2006). More detailed studies have found that gene expression patterns, epigenetic states, and telomere length status appeared to have been reversed in this reprogramming process (Buganim et al., 2012; Marion et al., 2009; Papp and Plath, 2013). iPSCs resemble ESCs in multiple molecular markers as well as in producing alliPSC mice by tetraploid complementation technique (Kang et al., 2009; Maherali et al., 2007; Mikkelsen et al., 2008; Takahashi and Yamanaka, 2006; Zhao et al., 2009).

How PSCs maintain their ability for self-renewal and pluripotency is a fundamental issue in cell biology. Studies in recent years have pointed to epigenetic mechanisms that could control the difference between PSCs and somatic cells. Compared with differentiated somatic cells, ESCs have unique features: they have a more "open" conformation of chromatin structure, including the telomeric region. The repressive histone modifications are less prevailing in the
ESC genome, compared to those in differentiated cells (Hawkins et al., 2010; Wen et al., 2009). Many transcription factors that control cell fate determination are epigenetically marked by either active (such as methylated $\mathrm{H} 3 \mathrm{~K} 4$ ) or repressive (like methylated H3K27) histone modifications. These bivalent chromatin states provide the plasticity for maintaining ESC pluripotency and regulating the expression level of lineage-specific genes during differentiation (Bernstein et al., 2006). For iPSCs, the epigenetic status of successfully induced cells is highly similar to the ESCs, including changes in histone modifications and DNA methylation at the gene loci that are required for the maintenance of pluripotency and lineage specification, as well as efficient activation of the telomerase and elongation of telomeres (Marion et al., 2009; Takahashi et al., 2007; Takahashi and Yamanaka, 2006).

In addition, ESCs may also have evolved more stringent mechanisms to protect genome integrity compared to differentiated cells. For example, ESCs harbor much lower mutation and recombination rate than somatic cells (Cervantes et al., 2002). Moreover, ESCs exhibit hypersensitivity to DNA damage, efficient DNA repair mechanisms and high proficiency in antioxidant defense, which also help to maintain their genome stability (Giachino et al., 2013). The long and stable telomeres often found in ESCs may be an additional mechanism to protect chromosomal integrity (Huang et al., 2011). The telomeres in PSCs, which can be regulated in a telomerase-dependent or independent (e.g. ALT) fashion, are crucial for PSC biology, which will be discussed in the following sections.

\section{TELOMERES IN PLURIPOTENT STEM CELLS}

While the telomere in somatic cells is usually composed of heterochromatin, the genome-wide chromatin structure is relatively open in PSCs. How is the status of telomeric chromatin in PSCs? Recent studies have shown that PSCs contain relatively "open" telomeric chromatin that would switch to become more repressive during differentiation (Azuara et al., 2006; Bernstein et al., 2006; Meshorer et al., 2006). Therefore, the telomeric chromatin of PSCs is likely in a unique and dynamic state that can undergo remodeling during differentiation (Marion et al., 2009; Wong et al., 2009).

One of the common characteristics of ESCs and iPSCs is the expression of transcription factors Oct4, Sox2, and $\mathrm{Na}-$ nog, as well as constitutively high telomerase activity. PSCs can use the telomerase pathway to elongate their telomeres (Blasco, 2007; Hiyama and Hiyama, 2007). The in vivo study of adult stem cells indicated that adequate telomere length is a prerequisite for the functionality of stem cells (Flores et al., 2008).

Dynamic telomere status is not restricted to the aging process, but is also found during embryo development and PSC derivation. At the preimplantation embryo stage, telomeres are effectively elongated by ALT-like mechanism from 

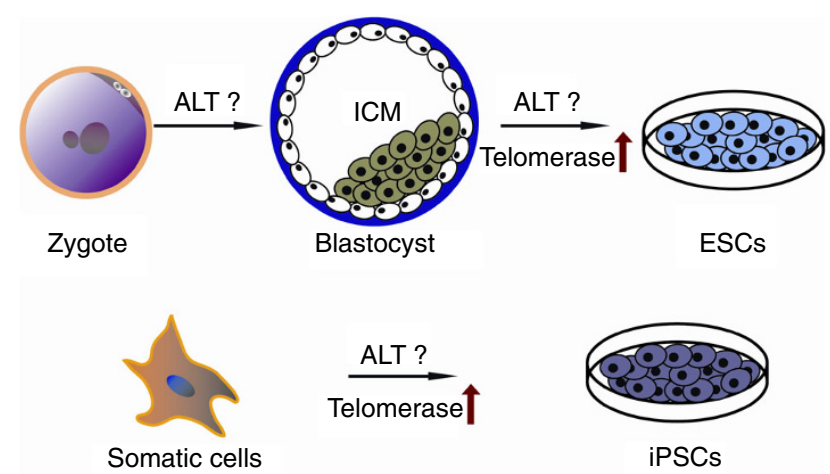

Telomere length

Figure 1. Telomere length increases during preimplantation embryo development and PSCs derivation process. At the embryo stage, telomeres are effectively elongated by a possible alternative lengthening of telomeres (ALT) pathway from zygote to blastocyst. However, during early expansion, ESCs obtained from the inner cell mass (ICM) in vitro continuously elongate their telomeres to a relatively stable level in a telomerasedependent way, and ALT pathway could not be excluded in this process. Similarly, both telomerase-dependent and independent mechanism may coexist in the iPSCs reprogramming process. In summary, the PSCs, including ESCs and iPSCs, need to elongate their telomeres during the derivation process to stabilize their genomic DNA and keep their self-renewal and pluripotency status.

totipotent zygote to blastocyst and then telomerase is used to maintain telomere length during ontogenesis in adult stem cells (Liu et al., 2007) (Fig. 1). Surprisingly, ICM cells in the blastocyst have different telomere length compared to ESCs -telomeres extend continuously during murine ESC derivation process. There may be multiple non-mutually exclusive mechanisms contributing to ESC telomere elongation: one is that both $\mathrm{H} 3 \mathrm{~K} 9$ me 3 and $\mathrm{H} 4 \mathrm{~K} 20$ me3 heterochromatic marks decrease at telomeres; second is high-level expression of TRF1 that facilitates proficient capping of the newly synthesized telomeres. These two factors ensured telomerase dependent elongating of the telomeres. More interestingly, an ALT-like mechanism is also activated during this process to rapidly elongate the telomeres, wherein Zscan4 is involved to maintain genomic stability, (Varela et al., 2011; Zalzman et al., 2010). Similarly, the study of human ESCs demonstrated that telomeres were elongated during early expansion in vitro and then reached to a relatively stable level in a telomerase-dependent way (Zeng et al., 2013). For self-renewal and developmental pluripotency, the ESC telomere state is tightly associated with its function. ESCs with short telomeres show reduced pluripotency as revealed by teratoma formation and chimera production in vivo (Huang et al., 2011). In Tert ${ }^{-/-}$ESCs, critically short telomeres induced de novo methyltransferase Dnmt3a2/3b downregulation, genome-wide DNA hypomethylation, and altered H3K27me3 enrichment at Nanog and Gata6 promoters as well as at loci distal to telomeres. These epigenetic changes in turn affect the stable differentiation ability of ESCs in vitro (Pucci et al., 2013).

During initial iPSC studies, researchers could easily and effectively obtain iPSCs by introducing the four Yamanaka factors into somatic cells. Most of these cell lines showed typical ESC-like colony shape, specific molecular markers such as Oct4, Nanog and Sox2, and positive alkaline phosphatase activity. However, most of these lines could not produce iPSC-mice by tetraploid complementation except chimeric mice, indicating that they were not entirely pluripotent. A recent report found that murine ESCs/iPSCs with short telomeres could not produce ESC/iPSC mice directly and the efficiency of teratoma formation and chimera production decreased significantly (Huang et al., 2011). Also the porcine iPSC studies found that telomere length is related to the efficiency of teratoma formation and ALT mechanism is also found in porcine iPSCs (Ji et al., 2013). Although with some controversy, telomeres can be elongated after somatic cell nuclear transfer (SCNT) process in many species (Jiang et al., 2004; Lanza et al., 2000; Shiels et al., 1999; Sparman et al., 2009). The Blasco group also observed extension of telomeres during iPSC derivation and passage (Marion et al., 2009) (Fig. 1). Recently, the comparison of the differences between the SCNT-mediated and iPSC-based reprogramming of $\mathrm{Terc}^{-/-}$cells found that SCNT is superior to iPSC mediated reprogramming in donor cells with telomere and mitochondria dysfunction, providing an application insight for reprogramming strategy optimization. (Le et al., 2014). Furthermore, ectopic expression of factors, which could protect telomeres such as Zscan4, can increase induction efficiency and pluripotency of iPSCs remarkably (Jiang et al., 2013). These lines of evidence demonstrate that telomere elongation and functional reconstruction is very important for iPSCs to acquire true pluripotency. In fact, the telomeres of iPSCs have been shown to be remodeled to features similar to ESCs by both telomerase-dependent and possible ALT pathway, in both mouse and human (Marion et al., 2009; Wang et al., 2012; Yehezkel et al., 2011) (Fig. 1).

On the other hand, telomere dysfunction can also impact cell metabolism through affecting mitochondrial function. Progressive telomere shortening limits the replication capacity of dividing cells such as stem cells (Cong et al., 2002), and induces p53 to repress PGC-1 $1 \alpha$ and PGC-1 $\beta$, thereby linking telomeres to mitochondrial biology, oxidative defense, and metabolism (Sahin et al., 2011). One of the core telomeric proteins TIN2 was recently shown to localize to mitochondria, and play an important role in mitochondrial function regulation. TIN2 appears to negatively modulate ATP production by limiting efficient electron transport and decreasing mitochondrial membrane potential (Chen et al., 2012). Whether mutations of TIN2 would affect the pluripotency of PSCs and the efficiency of iPSCs reprogramming in 
Tin2-related dyskeratosis congenital (DC) disease models need further investigation.

Although the mechanism of telomere regulation in the PSCs remains unclear, the following key modulators of ESCs/iPSCs telomere maintenance have been found so far which has expanded our understanding in this field.

\section{TELOMERASE IN PLURIPOTENT STEM CELLS}

The status of the telomerase is crucial for pluripotency of adult stem cells and tissue function. $\mathrm{Terc}^{-/-}$mice with null telomerase activity are viable for only six generations. These mice exhibit premature aging phenotypes such as gray hair, kyphosis, smaller body size and shorter life-span. Conversely, in Tert-overexpressing transgenic mice, telomerase reactivation can reverse tissue degeneration in hair follicles, testes, intestinal crypts and brain in aged telomerase-deficient mice (Flores et al., 2005; Jaskelioff et al., 2011).

Surprisingly, ESCs can be derived from $\mathrm{Terc}^{+/-}$and $\mathrm{Terc}^{-/-}$ mice as efficiently as wild type ESCs, indicating that the telomerase per se is not required for the establishment of ESC lines. The haplosufficient Terc ${ }^{+/-}$ESCs had significantly reduced ESC mice production efficiency compared with wild type ESCs. G1 Terc $^{-/-}$ESCs, derived from first generation $\mathrm{Terc}^{-/-}$mice with normal karyotypes and shorter telomeres, could not produce any ESC mice by 8-cell embryos injecton, even though G1 Terc $^{-/-}$ESCs could form teratomas as efficiently as $\mathrm{Terc}^{+/-}$and wild type ESCs. The ESCs from G4 $\mathrm{Terc}^{-/-}$mice display aneuploidy and chromosomal abnormalities and could not produce any chimeras (Huang et al., 2011).

Overexpression of telomerase in mouse and human ESCs appeared to improve their self-renewal, colony-formation capacity, resistance to apoptosis and proliferation rate. The Tert-overexpressing human ESCs are able to form teratomas composed of three germ layers in vivo, but their ability to differentiate into all primitive and embryonic lineages in vitro was suppressed (Armstrong et al., 2005; Yang et al., 2008). In summary, it appears that regulating telomerase activity appropriately in ESCs is critically important for maintaining ESC pluripotency and modulating their differentiation.

Other lines of evidence come from the telomerase-associated diseases. DC is a rare progressive congenital disorder with characteristics of high rates of bone marrow failure, pulmonary fibrosis, oral leukoplakia, nail dystrophy, abnormal skin pigmentation, etc. It is mainly caused by mutations in genes encoding the telomerase or telomerase-associated proteins such as DKC1, TERT, TERC, TCAB1 and RTEL1 (Ballew et al., 2013; Bessler et al., 2010; Walne and Dokal, 2009). These DC patients have very short telomeres in their peripheral blood lymphocytes (Alter et al., 2007). iPSC studies using fibroblasts from DC patients have shed light on the interplay between the telomerase and pluripotency establishment. Reprogrammed iPSCs from Terc destabilized DC patients could overcome the critical limitation in Terc levels to restore telomere maintenance and acquire selfrenewal capability (Agarwal et al., 2010). However, iPSCs from different types of DC patients retain the characteristic disease defects, and display telomere maintenance defects that correlate with their corresponding clinical severity (Batista et al., 2011). In most cases, both mutant and wild type iPSCs could upregulate Tert and Terc expression levels compared with parental somatic cells, but mutant iPSCs usually elongated telomeres at a lower rate compared to their wild type counterparts. Defective telomere elongation appears to have a definitive impact on the true pluripotency and differentiation abilities of iPSCs (Winkler et al., 2013).

During either ESCs establishment or iPSCs generation, the mechanism for elongating telomeres seems to be not confined to the telomerase pathway. When Terc-deleted ESCs went through crisis after multiple passages, survived ESCs were found to use ALT pathway to maintain telomeres (Niida et al., 2000). Moreover, although telomerase reactivation is necessary for reprogramming, ALT-dependent mechanism is also involved in reprogramming, in a nonsufficient way (Wang et al., 2012). These results underline the importance of both telomerase-dependent and independent pathways in the regulation of telomeres in PSCs (Fig. 1).

\section{ALTERNATIVE LENGTHENING OF TELOMERES (ALT) PATHWAY IN PLURIPOTENT STEM CELLS}

While $85 \%-90 \%$ of human cancers extend telomeres through the upregulation of telomerase activity, $10 \%-15 \%$ of cancers use the ALT pathway, a process that appears dependent on homologous recombination (Bryan et al., 1997; Shay and Bacchetti, 1997). Usually, the two telomere maintenance mechanisms appear mutually exclusive for most cells. Mutations of DAXX, ATRX and $H 3.3$ have also been found to be associated with telomerase-negative human cancer cells that undergo ALT (Schwartzentruber et al., 2012). However, ALT and telomerase pathways may coexist in PSCs, which was supported by the evidence that telomerase reactivation is accompanied by ALT during reprogramming and ALT-related H3.3/ATRX colocalize with telomere within the PML bodies in ESCs (Chang et al., 2013; Wang et al., 2012).

The histone $\mathrm{H} 3$ variant $\mathrm{H} 3.3$ was originally thought to be commonly associated with active chromatin. However, recent data have revealed that this particular variant can accumulate on silent loci in heterochromatin, indicating its possible dual roles in transcriptional regulation (Goldberg et al., 2010). Interestingly, it was found that H3.3 could localize to the telomeres in mouse ESCs and embryonic germ cells, but not in non-pluripotent cells. H3.3 levels decrease during ESCs differentiation while the heterochromatin repressive markers H4K2Ome3 and H3K9me3 increase in this process. Meanwhile, depletion of H3.3 could induce dysregulation of telomeres, providing evidence for a 
role of $\mathrm{H} 3.3$ in the regulation of telomere chromatin integrity in ESCs (Wong et al., 2009).

H3.3 can be found in two separate complexes, associating with either histone deposition factor HIRA or histone chaperone DAXX. The HIRA complex can deposit H3.3 at transcribed genes, whereas DAXX and ATRX together with H3.3 assemble at pericentric heterochromatin and telomeres. Strikingly, ATRX and DAXX associate with $\mathrm{H} 3.3$ in a HIRA-independent manner in ESCs, which may explain why H3.3 has dual roles at both active and repressed genes (Goldberg et al., 2010). ATRX, short for alpha thalassemia/ mental retardation syndrome $X$-linked gene, belongs to the SWI2/SNF2 family of chromatin remodeling proteins. In cooperation with $\mathrm{H} 3.3$ and HP1alpha, ATRX can modulate telomere chromatin status. ATRX knockdown led to increased DNA damage at the telomeres in ESCs, but not in cells such as NIH3T3, indicating a specific role for ATRX in ensuring the integrity of ESC telomere chromatin (Wong et al., 2010b). DAXX or death associated protein is a histone chaperone required for the deposition of $\mathrm{H} 3.3$ at telomeres in the context of the ATRX-DAXX complex (Drane et al., 2010; Lewis et al., 2010). Mutations in the ATRX/DAXX complex and histone $\mathrm{H} 3.3$ were found to correlate with features of ALT in many cancers (Heaphy et al., 2011; Schwartzentruber et al., 2012). A comprehensive analysis of several ALT cell lines has indicated that loss or mutations of ATRX are hallmarks of ALT cell lines. Additionally, genome instability and altered double-strand break (DSB) repair are also correlated with ALT (Lovejoy et al., 2012). Whether the ATRX/DAXX complex contributes to telomere regulation through the ALT pathway in ESCs needs further investigation.

In ESCs, H3.3, DAXX and ATRX can localize to the promyelocytic leukemia nuclear bodies (PML-NBs) and form ALT-associated PML-NBs (APBs), one of the hallmarks of ALT cells (Chang et al., 2013). Marked by PML and SP100, PML-NBs are subnuclear compartments in eukaryotic cells enriched in regulatory proteins that can modulate multiple cellular processes including gene transcription, tumor suppression, as well as DNA replication and repair (Bernardi and Pandolfi, 2007). The assembly of PML-NBs is correlated with the pluripotent state of mouse ESCs, suggesting the PML-NBs serve as important platforms for the study of telomeric chromatin integrity in ESCs (Chang et al., 2013). Future studies should focus on novel factors in the PML-NBs that regulate ESC telomeres and more details should be demonstrated to unmask the exact mechanism and function of the ALT pathway in PSCs.

\section{TELOMERE-ASSOCIATED REGULATORS IN PLURIPOTENT STEM CELLS}

As mentioned above, the epigenetic state of telomere chromatin may affect telomere length in PSCs. Several reports support the notion that multiple chromatin modulators may participate in the regulation of telomere structure and length.
SUV39H1 and SUV39H2, for example, are two histone methyltransferases required for the enrichment of trimethylated H3K9 on constitutive heterochromatin including both centromeres and telomeres. Suv39h1 and Suv39h2 double knockout led to loss of heterochromatic features and abnormal telomere elongation in murine ESCs and porcine embryonic stem like cells, respectively (Dang-Nguyen et al., 2013; Garcia-Cao et al., 2004). Similarly, SUV4-20H1 and SUV4-2OH2 are histone methyltransferases responsible for H4K20me3 level maintenance. Simultaneous loss of Suv4$20 \mathrm{~h} 1$ and Suv4-20h2 resulted in a considerable elongation of telomeres (Benetti et al., 2007b). Recently, it has also been found that abrogation of Suv4-20h decreases the heterochromatic mark $\mathrm{H} 4 \mathrm{~K} 20 \mathrm{me} 3$ at telomeric regions and facilitates telomere replenish during reprogramming (Marion et al., 2011). Consistently, relatively low density of H3K9me3 and $\mathrm{H} 4 \mathrm{~K} 20 \mathrm{me} 3$ was observed during reprogramming as well as in ESCs (Marion et al., 2009). This "relaxed" telomeric chromatin state may facilitate the access of telomerase to telomeres in PSCs and thus modulate telomere length.

DNA hypermethylation is another epigenetic feature at subtelomeric regions. The loss of DNA methyltransferases Dnmt1 or Dnmt3a/Dnmt3b in ESCs, which led to hypomethylated subtelomeric chromatin, caused dramatic telomere elongation by homologous recombination, and phenotypes similar to ALT cells, including increased T-SCE, APB formation and telomere heterogeneity. It should be noted that a possible role for the telomerase or other as yet unidentified regulators cannot be excluded in this process (Gonzalo et al., 2006).

Given the importance of telomere maintenance in PSCs, the factors that can regulate telomerase expression, recruitment and activity are also expected to play a significant part in PSCs. For example, the TPP1-POT1 heterodimer in the shelterin/telosome complex binds to single-stranded G-rich telomeric overhangs. TPP1-POT1 association can enhance POT1-DNA affinity and telomerase recruitment. TPP1 RNAi in cancer cells caused DNA damage response at the telomeres and led to telomere dysfunction (Xin et al., 2007). Indeed, abrogation of TPP1 also abolished telomere elongation during reprogramming of mouse embryonic fibroblast (MEF) cells, supporting a role of TPP1 in PSCs (Tejera et al., 2010). Several transcriptional regulators of the telomerase in PSCs have also been demonstrated. Hypoxia inducible factor 1 alpha (HIF1 $\alpha$ ) was identified as an upstream transactivator of Tert in response to hypoxia in mouse ESCs in a shRNA library screening. HIF1a loss in ESCs is accompanied by both decreased Tert level and shortened telomere length, which in turn can be restored by reintroducing HIFa level in a hypoxic condition (Coussens et al., 2010). Klf4, one of the four Yamanaka factors (Oct4, Sox2, KIf4, c-Myc), was found to specifically and directly activate the Tert promoter in ESCs. KIf4 knockdown in ESCs led to reduced Tert expression and ESC differentiation, whereas overexpression of Tert rescued these phenotypes 
(Wong et al., 2010a). In cooperation with Klf4, the classical multifunctional Wnt/ $\beta$-catenin signaling pathway can directly target Tert (Hoffmeyer et al., 2012). These data provide a direct link between PSC pluripotency and telomerase activity regulation.

In addition, novel factors have been found to take part in telomere regulation in PSCs as well. For example, zinc finger and SCAN domain containing 4 (Zscan4) is a gene cluster that contains six members, and expressed specifically in late 2-cell embryos and ESCs (Falco et al., 2007). It was found that Zscan4 could elongate telomeres in ESCs by homologous recombination and form foci on telomeres. Thus Zscan4 facilitates and maintains genome stability in ESCs in a telomerase-independent manner (Zalzman et al., 2010). Further studies in reprogramming demonstrate a consistent role of Zscan4 in protecting genome stability of PSCs, and Zscan4 overexpression could rejuvenate the developmental potency of PSCs in long-term cell culture (Amano et al., 2013; Jiang et al., 2013). The precise molecular functions of Zscan4 in the possible ALT pathway in PSCs are still unclear. The investigation of Zscan4 and other novel factors should greatly facilitate our understanding of PSC telomere maintenance mechanism.

\section{PROSPECT}

Multiple links between telomere biology and stem cell pluripotency have been established. Interestingly, the longest telomeres appear to exist in adult stem cells where they become shortened as stem cell function declines. Additionally, higher expression of the shelterin/telosome complex component TRF1 correlates with higher pluripotency of stem cells. Consequently, long telomeres and high TRF1 level have been proposed as stem cell markers (Flores et al., 2008; Huang et al., 2011; Schneider et al., 2013). Indeed, telomere status may serve as a benchmark to evaluate the quality of ESCs and iPSCs, which should have important implications in the application of PSCs in regenerative medicine (Fig. 1). Compared with somatic cells, PSCs have unique combinations of telomere-associated proteins. Elucidating the function of these factors, particularly their specific roles in regulating PSC telomeres would be a top priority. Finally, further understanding of how and why PSCs maintain their telomeres through both the telomerase and possible ALT pathway promises great insight into the complicated mechanisms that establish and ensure pluripotency of stem cells.

\section{ACKNOWLEDGMENTS}

This study was supported by the National Basic Research Program (973 Program) (Nos. 2010CB945401 and 2012CB911201), the National Natural Science Foundation of China (Grant Nos. 31371508, 31000611 and 91019020), Introduced Innovative R\&D Team of Guangdong Province (201001Y0104687244), Zhujiang
Program of Science and Technology Nova in Guangzhou (2011J2200082) and "985" project foundation of Sun Yat-sen University (33000-3281303).

\section{ABBREVIATIONS}

ALT, alternative lengthening of telomeres; DC, dyskeratosis congenital; DSB, double-strand break; ESCs, embryonic stem cells; ICM, inner cell mass; iPSCs, induced pluripotent stem cells; MEF, mouse embryonic fibroblast; PML, promyelocytic leukemia; PSCs, pluripotent stem cells.

\section{COMPLIANCE WITH ETHICS GUIDELINES}

Yan Huang, Puping Liang, Dan Liu, Junjiu Huang and Zhou Songyang declare that they have no conflict of interest.

This article does not contain any studies with human or animal subjects performed by the any of the authors.

\section{OPEN ACCESS}

This article is distributed under the terms of the Creative Commons Attribution License which permits any use, distribution, and reproduction in any medium, provided the original author(s) and the source are credited.

\section{REFERENCES}

Agarwal S, Loh YH, McLoughlin EM, Huang J, Park IH, Miller JD, Huo H, Okuka M, Dos Reis RM, Loewer S et al (2010) Telomere elongation in induced pluripotent stem cells from dyskeratosis congenita patients. Nature 464:292-296

Alter BP, Baerlocher GM, Savage SA, Chanock SJ, Weksler BB, Willner JP, Peters JA, Giri N, Lansdorp PM (2007) Very short telomere length by flow fluorescence in situ hybridization identifies patients with dyskeratosis congenita. Blood 110:1439-1447

Amano T, Hirata T, Falco G, Monti M, Sharova LV, Amano M, Sheer S, Hoang HG, Piao Y, Stagg CA et al (2013) Zscan4 restores the developmental potency of embryonic stem cells. Nat Commun 4:1966

Armstrong L, Saretzki G, Peters H, Wappler I, Evans J, Hole N, von Zglinicki T, Lako M (2005) Overexpression of telomerase confers growth advantage, stress resistance, and enhanced differentiation of ESCs toward the hematopoietic lineage. Stem Cells 23:516-529

Azuara V, Perry P, Sauer S, Spivakov M, Jorgensen HF, John RM, Gouti M, Casanova M, Warnes G, Merkenschlager M et al (2006) Chromatin signatures of pluripotent cell lines. Nat Cell Biol 8:532538

Ballew BJ, Yeager M, Jacobs K, Giri N, Boland J, Burdett L, Alter BP, Savage SA (2013) Germline mutations of regulator of telomere elongation helicase 1, RTEL1, in Dyskeratosis congenita. Hum Genet 132:473-480

Batista LF, Pech MF, Zhong FL, Nguyen HN, Xie KT, Zaug AJ, Crary SM, Choi J, Sebastiano V, Cherry A et al (2011) Telomere shortening and loss of self-renewal in dyskeratosis congenita induced pluripotent stem cells. Nature 474:399-402

Benetti R, Garcia-Cao M, Blasco MA (2007a) Telomere length regulates the epigenetic status of mammalian telomeres and subtelomeres. Nat Genet 39:243-250 
Benetti R, Gonzalo S, Jaco I, Schotta G, Klatt P, Jenuwein T, Blasco MA (2007b) Suv4-20h deficiency results in telomere elongation and derepression of telomere recombination. J Cell Biol 178:925936

Bernardi R, Pandolfi PP (2007) Structure, dynamics and functions of promyelocytic leukaemia nuclear bodies. Nat Rev Mol Cell Biol 8:1006-1016

Bernstein BE, Mikkelsen TS, Xie X, Kamal M, Huebert DJ, Cuff J, Fry B, Meissner A, Wernig M, Plath K et al (2006) A bivalent chromatin structure marks key developmental genes in embryonic stem cells. Cell 125:315-326

Bessler M, Wilson DB, Mason PJ (2010) Dyskeratosis congenita. FEBS Lett 584:3831-3838

Blasco MA (2007) Telomere length, stem cells and aging. Nat Chem Biol 3:640-649

Blasco MA, Lee HW, Hande MP, Samper E, Lansdorp PM, DePinho RA, Greider CW (1997) Telomere shortening and tumor formation by mouse cells lacking telomerase RNA. Cell 91:25-34

Bryan TM, Englezou A, Dalla-Pozza L, Dunham MA, Reddel RR (1997) Evidence for an alternative mechanism for maintaining telomere length in human tumors and tumor-derived cell lines. Nat Med 3:1271-1274

Buganim Y, Faddah DA, Cheng AW, Itskovich E, Markoulaki S, Ganz K, Klemm SL, van Oudenaarden A, Jaenisch R (2012) Single-cell expression analyses during cellular reprogramming reveal an early stochastic and a late hierarchic phase. Cell 150:1209-1222

Cerone MA, Londono-Vallejo JA, Bacchetti S (2001) Telomere maintenance by telomerase and by recombination can coexist in human cells. Hum Mol Genet 10:1945-1952

Cervantes RB, Stringer JR, Shao C, Tischfield JA, Stambrook PJ (2002) Embryonic stem cells and somatic cells differ in mutation frequency and type. Proc Natl Acad Sci USA 99:3586-3590

Cesare AJ, Reddel RR (2010) Alternative lengthening of telomeres: models, mechanisms and implications. Nat Rev Genet 11:319330

Chang FT, McGhie JD, Chan FL, Tang MC, Anderson MA, Mann JR, Andy Choo KH, Wong LH (2013) PML bodies provide an important platform for the maintenance of telomeric chromatin integrity in embryonic stem cells. Nucleic Acids Res 41:44474458

Chen LY, Zhang Y, Zhang Q, Li H, Luo Z, Fang H, Kim SH, Qin L, Yotnda P, Xu J et al (2012) Mitochondrial localization of telomeric protein TIN2 links telomere regulation to metabolic control. Mol Cell 47:839-850

Chung I, Osterwald S, Deeg KI, Rippe K (2012) PML body meets telomere: the beginning of an ALTernate ending? Nucleus 3:263275

Cohen SB, Graham ME, Lovrecz GO, Bache N, Robinson PJ, Reddel RR (2007) Protein composition of catalytically active human telomerase from immortal cells. Science 315:1850-1853

Cong YS, Wright WE, Shay JW (2002) Human telomerase and its regulation. Microbiol Mol Biol Rev 66:407-425

Coussens M, Davy P, Brown L, Foster C, Andrews WH, Nagata M, Allsopp R (2010) RNAi screen for telomerase reverse transcriptase transcriptional regulators identifies HIF1alpha as critical for telomerase function in murine embryonic stem cells. Proc Natl Acad Sci USA 107:13842-13847
Dang-Nguyen TQ, Haraguchi S, Furusawa T, Somfai T, Kaneda M, Watanabe S, Akagi S, Kikuchi K, Tajima A, Nagai T (2013) Downregulation of histone methyltransferase genes SUV39H1 and SUV39H2 increases telomere length in embryonic stem-like cells and embryonic fibroblasts in pigs. J Reprod Dev 59:27-32

de Lange T (2005) Shelterin: the protein complex that shapes and safeguards human telomeres. Gene Dev 19:2100-2110

Drane P, Ouararhni K, Depaux A, Shuaib M, Hamiche A (2010) The death-associated protein DAXX is a novel histone chaperone involved in the replication-independent deposition of H3.3. Gene Dev 24:1253-1265

Evans MJ, Kaufman MH (1981) Establishment in culture of pluripotential cells from mouse embryos. Nature 292:154-156

Falco G, Lee SL, Stanghellini I, Bassey UC, Hamatani T, Ko MS (2007) Zscan4: a novel gene expressed exclusively in late 2-cell embryos and embryonic stem cells. Dev Biol 307:539-550

Flores I, Cayuela ML, Blasco MA (2005) Effects of telomerase and telomere length on epidermal stem cell behavior. Science 309:1253-1256

Flores I, Canela A, Vera E, Tejera A, Cotsarelis G, Blasco MA (2008) The longest telomeres: a general signature of adult stem cell compartments. Genes Dev 22:654-667

Garcia-Cao M, O'Sullivan R, Peters AH, Jenuwein T, Blasco MA (2004) Epigenetic regulation of telomere length in mammalian cells by the Suv39h1 and Suv39h2 histone methyltransferases. Nat Genet 36:94-99

Giachino C, Orlando L, Turinetto V (2013) Maintenance of genomic stability in mouse embryonic stem cells: relevance in aging and disease. Int J Mol Sci 14:2617-2636

Goldberg AD, Banaszynski LA, Noh KM, Lewis PW, Elsaesser SJ, Stadler S, Dewell S, Law M, Guo XY, Li X et al (2010) Distinct factors control histone variant $\mathrm{H} 3.3$ localization at specific genomic regions. Cell 140:678-691

Gonzalo S, Garcia-Cao M, Fraga MF, Schotta G, Peters AHFM, Cotter SE, Eguia R, Dean DC, Esteller M, Jenuwein T et al (2005) Role of the RB1 family in stabilizing histone methylation at constitutive heterochromatin. Nat Cell Biol 7:U420-U452

Gonzalo S, Jaco I, Fraga MF, Chen T, Li E, Esteller M, Blasco MA (2006) DNA methyltransferases control telomere length and telomere recombination in mammalian cells. Nat Cell Biol 8:416424

Greider CW, Blackburn EH (1985) Identification of a specific telomere terminal transferase activity in Tetrahymena extracts. Cell 43:405-413

Greider CW, Blackburn EH (1989) A telomeric sequence in the RNA of Tetrahymena telomerase required for telomere repeat synthesis. Nature 337:331-337

Hawkins RD, Hon GC, Lee LK, Ngo Q, Lister R, Pelizzola M, Edsall LE, Kuan S, Luu Y, Klugman S et al (2010) Distinct epigenomic landscapes of pluripotent and lineage-committed human cells. Cell Stem Cell 6:479-491

Heaphy CM, de Wilde RF, Jiao Y, Klein AP, Edil BH, Shi C, Bettegowda C, Rodriguez FJ, Eberhart CG, Hebbar S et al (2011) Altered telomeres in tumors with ATRX and DAXX mutations. Science 333:425

Henson JD, Hannay JA, McCarthy SW, Royds JA, Yeager TR, Robinson RA, Wharton SB, Jellinek DA, Arbuckle SM, Yoo JY 
et al (2005) A robust assay for alternative lengthening of telomeres in tumors shows the significance of alternative lengthening of telomeres in sarcomas and astrocytomas. Clin Cancer Res 11:217-225

Herrera E, Samper E, Martin-Caballero J, Flores JM, Lee HW, Blasco MA (1999) Disease states associated with telomerase deficiency appear earlier in mice with short telomeres. EMBO J 18:2950-2960

Hiyama E, Hiyama K (2007) Telomere and telomerase in stem cells. Br J Cancer 96:1020-1024

Hoffmeyer K, Raggioli A, Rudloff S, Anton R, Hierholzer A, Del Valle I, Hein K, Vogt R, Kemler R (2012) Wnt/beta-catenin signaling regulates telomerase in stem cells and cancer cells. Science 336:1549-1554

Huang J, Wang F, Okuka M, Liu N, Ji G, Ye X, Zuo B, Li M, Liang P, Ge WW et al (2011) Association of telomere length with authentic pluripotency of ES/iPS cells. Cell Res 21:779-792

Jaskelioff M, Muller FL, Paik JH, Thomas E, Jiang S, Adams AC, Sahin E, Kost-Alimova M, Protopopov A, Cadinanos J et al (2011) Telomerase reactivation reverses tissue degeneration in aged telomerase-deficient mice. Nature 469:102-106

Ji G, Ruan W, Liu K, Wang F, Sakellariou D, Chen J, Yang Y, Okuka M, Han J, Liu Z et al (2013) Telomere reprogramming and maintenance in porcine iPS cells. PLoS One 8:e74202

Jiang L, Carter DB, Xu J, Yang X, Prather RS, Tian XC (2004) Telomere lengths in cloned transgenic pigs. Biol Reprod 70 : 1589-1593

Jiang J, Lv W, Ye X, Wang L, Zhang M, Yang H, Okuka M, Zhou C, Zhang X, Liu L et al (2013) Zscan4 promotes genomic stability during reprogramming and dramatically improves the quality of iPS cells as demonstrated by tetraploid complementation. Cell Res 23:92-106

Kang L, Wang JL, Zhang Y, Kou ZH, Gao SR (2009) iPS cells can support full-term development of tetraploid blastocyst-complemented embryos. Cell Stem Cell 5:135-138

Lachner M, O'Carroll D, Rea S, Mechtler K, Jenuwein T (2001) Methylation of histone $\mathrm{H} 3$ lysine 9 creates a binding site for HP1 proteins. Nature 410:116-120

Lanza RP, Cibelli JB, Blackwell C, Cristofalo VJ, Francis MK, Baerlocher GM, Mak J, Schertzer M, Chavez EA, Sawyer N et al (2000) Extension of cell life-span and telomere length in animals cloned from senescent somatic cells. Science 288: 665-669

Le R, Kou Z, Jiang Y, Li M, Huang B, Liu W, Li H, Kou X, He W, Rudolph KL, Ju Z, Gao S (2014) Enhanced telomere rejuvenation in pluripotent cells reprogrammed via nuclear transfer relative to induced pluripotent stem cells. Cell Stem Cell 14:27-39

Lewis PW, Elsaesser SJ, Noh KM, Stadler SC, Allis CD (2010) Daxx is an H3.3-specific histone chaperone and cooperates with ATRX in replication-independent chromatin assembly at telomeres. Proc Natl Acad Sci USA 107:14075-14080

Liu D, O'Connor MS, Qin J, Songyang Z (2004) Telosome, a mammalian telomere-associated complex formed by multiple telomeric proteins. J Biol Chem 279:51338-51342

Liu L, Bailey SM, Okuka M, Munoz P, Li C, Zhou L, Wu C, Czerwiec E, Sandler L, Seyfang A et al (2007) Telomere lengthening early in development. Nat Cell Biol 9:1436-1441
Lopez-Otin C, Blasco MA, Partridge L, Serrano M, Kroemer G (2013) The hallmarks of aging. Cell 153:1194-1217

Lovejoy CA, Li W, Reisenweber S, Thongthip S, Bruno J, de Lange T, De S, Petrini JH, Sung PA, Jasin M et al (2012) Loss of ATRX, genome instability, and an altered DNA damage response are hallmarks of the alternative lengthening of telomeres pathway. PLoS Genet 8:e1002772

Maherali N, Sridharan R, Xie W, Utikal J, Eminli S, Arnold K, Stadtfeld M, Yachechko R, Tchieu J, Jaenisch R et al (2007) Directly reprogrammed fibroblasts show global epigenetic remodeling and widespread tissue contribution. Cell Stem Cell 1:55-70

Marion RM, Strati K, Li H, Tejera A, Schoeftner S, Ortega S, Serrano M, Blasco MA (2009) Telomeres acquire embryonic stem cell characteristics in induced pluripotent stem cells. Cell Stem Cell 4:141-154

Marion RM, Schotta G, Ortega S, Blasco MA (2011) Suv4-20h abrogation enhances telomere elongation during reprogramming and confers a higher tumorigenic potential to iPS cells. PLoS One 6:e25680

Martin GR (1981) Isolation of a pluripotent cell line from early mouse embryos cultured in medium conditioned by teratocarcinoma stem cells. Proc Natl Acad Sci USA 78:7634-7638

Mason PJ, Wilson DB, Bessler M (2005) Dyskeratosis congenita-a disease of dysfunctional telomere maintenance. Curr Mol Med 5:159-170

Meshorer E, Yellajoshula D, George E, Scambler PJ, Brown DT, Misteli T (2006) Hyperdynamic plasticity of chromatin proteins in pluripotent embryonic stem cells. Dev Cell 10:105-116

Mikkelsen TS, Hanna J, Zhang XL, Ku MC, Wernig M, Schorderet P, Bernstein BE, Jaenisch R, Lander ES, Meissner A (2008) Dissecting direct reprogramming through integrative genomic analysis. Nature 454:U41-U49

Neumann AA, Watson CM, Noble JR, Pickett HA, Tam PP, Reddel $R R$ (2013) Alternative lengthening of telomeres in normal mammalian somatic cells. Genes Dev 27:18-23

Niida H, Shinkai Y, Hande MP, Matsumoto T, Takehara S, Tachibana M, Oshimura M, Lansdorp PM, Furuichi Y (2000) Telomere maintenance in telomerase-deficient mouse embryonic stem cells: characterization of an amplified telomeric DNA. Mol Cell Biol 20:4115-4127

Papp B, Plath K (2013) Epigenetics of reprogramming to induced pluripotency. Cell 152:1324-1343

Pucci F, Gardano L, Harrington L (2013) Short telomeres in ESCs lead to unstable differentiation. Cell Stem Cell 12:479-486

Sahin E, Colla S, Liesa M, Moslehi J, Muller FL, Guo M, Cooper M, Kotton D, Fabian AJ, Walkey C et al (2011) Telomere dysfunction induces metabolic and mitochondrial compromise. Nature 470:359-365

Scheel C, Schaefer KL, Jauch A, Keller M, Wai D, Brinkschmidt C, van Valen F, Boecker W, Dockhorn-Dworniczak B, Poremba C (2001) Alternative lengthening of telomeres is associated with chromosomal instability in osteosarcomas. Oncogene 20:38353844

Schneider RP, Garrobo I, Foronda M, Palacios JA, Marion RM, Flores I, Ortega S, Blasco MA (2013) TRF1 is a stem cell marker and is essential for the generation of induced pluripotent stem cells. Nat Commun 4:1946 
Schwartzentruber J, Korshunov A, Liu XY, Jones DT, Pfaff E, Jacob K, Sturm D, Fontebasso AM, Quang DA, Tonjes M et al (2012) Driver mutations in histone $\mathrm{H} 3.3$ and chromatin remodelling genes in paediatric glioblastoma. Nature 482:226-231

Shay JW, Bacchetti S (1997) A survey of telomerase activity in human cancer. Eur J Cancer 33:787-791

Shiels PG, Kind AJ, Campbell KH, Waddington D, Wilmut I, Colman A, Schnieke AE (1999) Analysis of telomere lengths in cloned sheep. Nature 399:316-317

Sparman M, Dighe V, Sritanaudomchai H, Ma H, Ramsey C, Pedersen D, Clepper L, Nighot P, Wolf D, Hennebold $\mathrm{J}$ et al (2009) Epigenetic reprogramming by somatic cell nuclear transfer in primates. Stem Cells 27:1255-1264

Takahashi K, Yamanaka S (2006) Induction of pluripotent stem cells from mouse embryonic and adult fibroblast cultures by defined factors. Cell 126:663-676

Takahashi K, Tanabe K, Ohnuki M, Narita M, Ichisaka T, Tomoda K, Yamanaka S (2007) Induction of pluripotent stem cells from adult human fibroblasts by defined factors. Cell 131:861-872

Tejera AM, Stagno d'Alcontres M, Thanasoula M, Marion RM, Martinez P, Liao C, Flores JM, Tarsounas M, Blasco MA (2010) TPP1 is required for TERT recruitment, telomere elongation during nuclear reprogramming, and normal skin development in mice. Dev Cell 18:775-789

Varela E, Schneider RP, Ortega S, Blasco MA (2011) Different telomere-length dynamics at the inner cell mass versus established embryonic stem (ES) cells. Proc Natl Acad Sci USA 108:15207-15212

Walne AJ, Dokal I (2009) Advances in the understanding of dyskeratosis congenita. Br J Haematol 145:164-172

Wang F, Yin Y, Ye X, Liu K, Zhu H, Wang L, Chiourea M, Okuka M, Ji $G$, Dan J et al (2012) Molecular insights into the heterogeneity of telomere reprogramming in induced pluripotent stem cells. Cell Res 22:757-768

Wen B, Wu H, Shinkai Y, Irizarry RA, Feinberg AP (2009) Large histone $\mathrm{H} 3$ lysine 9 dimethylated chromatin blocks distinguish differentiated from embryonic stem cells. Nat Genet 41:246250

Winkler T, Hong SG, Decker JE, Morgan MJ, Wu C, Hughes WMt, Yang Y, Wangsa D, Padilla-Nash HM, Ried T et al (2013)
Defective telomere elongation and hematopoiesis from telomerase-mutant aplastic anemia iPSCs. J Clin Invest 123:1952-1963

Wong LH, Ren H, Williams E, McGhie J, Ahn S, Sim M, Tam A, Earle E, Anderson MA, Mann J et al (2009) Histone H3.3 incorporation provides a unique and functionally essential telomeric chromatin in embryonic stem cells. Genome Res 19:404-414

Wong CW, Hou PS, Tseng SF, Chien CL, Wu KJ, Chen HF, Ho HN, Kyo S, Teng SC (2010a) Kruppel-like transcription factor 4 contributes to maintenance of telomerase activity in stem cells. Stem Cells 28:1510-1517

Wong LH, McGhie JD, Sim M, Anderson MA, Ahn S, Hannan RD, George AJ, Morgan KA, Mann JR, Choo KH (2010b) ATRX interacts with $\mathrm{H} 3.3$ in maintaining telomere structural integrity in pluripotent embryonic stem cells. Genome Res 20:351-360

Xin HW, Liu D, Wan M, Safari A, Kim H, Sun W, O'Connor MS, Zhou SY (2007) TPP1 is a homologue of ciliate TEBP-beta and interacts with POT1 to recruit telomerase. Nature 445:559-562

Xin H, Liu D, Songyang Z (2008) The telosome/shelterin complex and its functions. Genome Biol 9:232

Yang CB, Przyborski S, Cooke MJ, Zhang X, Stewart R, Anyfantis G, Atkinson SP, Saretzki G, Armstrong L, Lako M (2008) A key role for telomerase reverse transcriptase unit in modulating human embryonic stem cell proliferation, cell cycle dynamics, and in vitro differentiation. Stem Cells 26:850-863

Yehezkel S, Rebibo-Sabbah A, Segev Y, Tzukerman M, Shaked R, Huber I, Gepstein L, Skorecki K, Selig S (2011) Reprogramming of telomeric regions during the generation of human induced pluripotent stem cells and subsequent differentiation into fibroblast-like derivatives. Epigenetics 6:63-75

Zalzman M, Falco G, Sharova LV, Nishiyama A, Thomas M, Lee SL, Stagg CA, Hoang HG, Yang HT, Indig FE et al (2010) Zscan4 regulates telomere elongation and genomic stability in ES cells. Nature 464:858-863

Zeng S, Liu L, Sun Y, Xie P, Hu L, Yuan D, Chen D, Ouyang Q, Lin G, Lu G (2013) Telomerase-mediated telomere elongation from human blastocysts to embryonic stem cells. J Cell Sci. doi:10. 1242/jcs. 131433

Zhao XY, Li W, Lv Z, Liu L, Tong M, Hai T, Hao J, Guo CL, Ma QW, Wang $L$ et al (2009) iPS cells produce viable mice through tetraploid complementation. Nature 461:U86-U88 